\title{
Performance of Avocado (Persea americana Mill.) and Mango (Mangifera indica L.) Seedlings Compared with Their Grafted Trees
}

\author{
Emanuel Lahav and Eli Tomer \\ Department of Fruit Trees, Agricultural Research Organization, The Volcani Center, P. O. Box 6, Bet \\ Dagan 50250, Israel
}

\author{
Shmuel Gazit \\ Department of Horticulture, The Hebrew University, Faculty of Agriculture, P.O. Box 12, Rehovot \\ 76100, Israel
}

Uri Lavi

Department of Fruit Tree Breeding and Genetics, Agricultural Research Organization, The Volcani Center, P.O. Box 6, Bet Dagan 50250, Israel

Additional index words. fruit breeding

\begin{abstract}
Most fruit-tree breeding projects are based on selection of seedlings in regard to their performance. The selected seedlings are vegetatively propagated, usually by grafting. It is highly important for the breeder to know whether the performance of the grafted tree will resemble the performance of the original seedling. In this study the performance of avocado and mango seedlings was compared with that of their grafted duplicates. Significant differences were found in only 8 out of 36 avocado traits and 2 out of 10 mango traits. Significant seedling $x$ graft interaction was detected in 10 other avocado traits. These differences were considered of no practical significance, since their magnitude was of minor importance for the breeder. The conclusion for avocado and mango breeders is that for most traits selection could be carried out on ungrafted seedlings.
\end{abstract}

In most 11-unit tree breeding projects, the testing phase is based on vegetative propagation of selected seedlings, usually by grafting. It is known though, that the perfomance of a grafted tree results from the interaction of the rootstock and the scion (Ben-Ya'acov, 1987: Rom and Carlson, 1987). Rootstock affect the adaptability of the tree to various soil conditions such as drought, flooding, salinity, and alkalinity (Rom and Carlson, 1987). Scion vigor, manifested principally in tree size, is well known to be affected by rootstock $x$ scion interaction. Since the fifteenth century, the use of rootstock to dwarf trees bits become a common practice, and it has been widely used in this century (Tukey, 1964). A dwarfing rootstock tends to reduce seasonal shoot extension of the scion. Such trees are characterized by heavy production at an early age. This is exemplified in the case of apple trees grafted on East Malling IX rootstock, which reach only about one third of the normal size and produce fruit at an early age. Rootstocks may also affect ripening time, fruit color, and fruit size (Rem and Carlson. 1987: Wutscher, 1979).

Rootstock are of great importance in the modern intensive culture of avocado. The practice of avocado grafting started in Florida at the beginning of this century (Popenoe, 1939). Avocado rootstock have been selected in California for their relative tolerance to phytophthora root rot (Coffey, 1987) and in Israel for [heir higher tolerance to salinity (Kadman and Ben Ya'acov. 1976) and calcareous soils (Ben-Ya'acov et al., 1979). Avocado rootstock have been reported to influence tree size and productivity. Tree size has been found to be affected by rootstock in California (Bergh and Whitsell, 1962). In a large-scale research project on rootstockscion relationship conducted in Israel, rootstock have been found to significantly affect avocado tree size and productivity (BenYa'acov 1972; Ben-Ya'acov et al., 1979). Tomer and Rotem ( 1989) found 'Degania 400' seedling rootstock to produce larger trees with higher production than 'Nahlat 3'. Rootstock may have also influenced avocado productivity; trees budded on 'Nabal' seedlings have given appreciably higher yields than those budded on four other rootstock (Oppenheimer, 1960).

As for mango, Oppenheimer (1958) compared three polyembryonic rootstock in Israel and found 'Sabre' to be superior in growth find production to ' Warburg' and ' 14.12 '. In a second trial trees grafted on two other rootstocks ('14.6' and '14.7') were equal to 'Sabre' in yields, while trees grafted on '3.2' and '14.12' were less productive (Oppenheimer, 1968). Giri and Yacub (1965) reported that polyembryonic mango rootstock delivered more vigor to the scions, compared with monoembryonic rootstocks. Swamy et al. ( 1972) reported that mango vigor and yield are not always controlled by the rootstock, while Sen (1939) and Janhati (1972) suggested that the scion (and not the rootstock) is responsible for the tree shape.

Most truit-tree breeding projects utilize the selection of the best performing non juvenile seedlings, concerning agriculturally important traits. These seedlings are then vegetatively propagated, usually by grafting, to allow a more thorough assessment. Since the first-stage selection is carried out on nongrafted seedlings, it is bight y important for the breeder to be aware of any potential effect on performance caused by either the rootstock or the rootstock $\times$ scion interaction. Obviously, in cases where such an effect is expected, much caution is needed at the seedling selection stage. This study was conducted to determine the potential effect of grafting on the performance of avocado and mango seedlings. 


\section{Materials and Methods}

Assessment of avocado seedlings and their grafted trees was carried out at the Akko Experiment Station in western Galilee, Israel (Lavi et al., 1990). Seedlings were planted in breeding plots at distances of $4 \mathrm{~m}$ between double rows of $2 \times 1 \mathrm{~m}$. The juvenile period was shortened by the use of autumn girdling (Lahav et al., 1986). Seedlings with outstanding fruit characteristics and produc - tivity were grafted in the nursery and also topworked on Mexican and/or West-Indian seedling rootstock. Each of the selected seedlings was grafted on two to four rootstock types (one to four seedlings each). Seventy original seedlings and their grafted duplicates were assessed for thirty-six traits (Table 1).

Productivity, one of the economically most important traits, was compared in a larger population of 229 graft-seedling pairs. These included the above mentioned 70 seedlings which were

Table 1. Avocado traits analysed in comparison of seedlings and grafted plants.

\begin{tabular}{|c|c|}
\hline Trait & Degrees of evaluation \\
\hline \multicolumn{2}{|l|}{ Tree } \\
\hline Tree habit & Upright (1); Branching (2); Spreading(3); Weeping (4) \\
\hline Tree size & Very big (1); Big (2); Medium (3); Small (4): Dwarf (5) \\
\hline Foliage density & Dense (1); Medium (2); Thin (3) \\
\hline Mature leaf color & Light-green (1); Green (2); Dark-green (3) \\
\hline Flush color & $\begin{array}{l}\text { Green (1): Greenish-brown (2); Brown (3); Brownish-red (4); Red (5); Reddish-green (6)'; Yellow } \\
(7)^{z} \text {; Yellowish-green }(8)^{z} \text {; Yellow-red }(9)^{z}\end{array}$ \\
\hline Brownish-red lenticels on young shoots & Numerous (1); medium (2): Few (3); None(4); Difficult to determine $(5)^{\mathrm{z}}$ \\
\hline \multicolumn{2}{|r|}{${ }^{2}$} \\
\hline Size & Very large (1); Large (2); Medium (3); Small; (4): Very small (5) \\
\hline Margin & Straight (1); Other (2) \\
\hline Anise odor & Strong (1): Medium (2); Weak (3): None (4) \\
\hline \multicolumn{2}{|l|}{ Flowering } \\
\hline Intensity & Profuse (1); High (2); Medium (3); Light (4); Very light (5); None (6) \\
\hline Time & Precocious (1); Early (2) Early-mid season; (3); Late-mid season (4); Late (5); Very late (6) \\
\hline \multicolumn{2}{|l|}{ Fruit and production } \\
\hline Weight & In grams \\
\hline Size uniformity & High (1); Medium (2); None (3) \\
\hline Shape uniformity & High (1); Medium (2); Slight (3) \\
\hline Density on the tree & Dense ( I); Medium (2): Light (3); Very light (4) \\
\hline \multicolumn{2}{|l|}{ Fruit stalk } \\
\hline Length of peduncle & $<5 \mathrm{~cm}(1) ; 6-10 \mathrm{~cm}(2) ; 11-15 \mathrm{~cm}(3) ; 16-20 \mathrm{~cm}(4):>20 \mathrm{~cm}(5)$ \\
\hline Length of pedicel & $<5 \mathrm{~mm}(1) ; 6-10 \mathrm{~mm}(2):$ I $1-15 \mathrm{~mm}(3) ; 16-20 \mathrm{~mm}(4):>20 \mathrm{~mm}(5)$ \\
\hline Attachment of stalk & Central (1); Slightly asymmetrical (2); Strongly asymmetrical (3) \\
\hline Thickness of stalk (in relation to fruit size) & Thick (1); Medium (2); Thin (3) \\
\hline Damage by snap-picking & Minimal (1); Slight (2); Medium-severe (3) \\
\hline \multicolumn{2}{|l|}{ Softened fruit } \\
\hline \multicolumn{2}{|l|}{ Skin } \\
\hline Gloss & High (1); Medium (2); Slight (3); Matte (4) \\
\hline Surface & $\begin{array}{l}\text { Smooth (1); Slightly rough (2); Rough (3): Slightly pimpled (4); Medium pimpled (5); Heavily } \\
\text { pimpled (6) }\end{array}$ \\
\hline Thickness & $\begin{array}{l}\text { Mexican type (1); Like 'Fuerte' (2); Like 'Tova' (3); Like 'Hass' (4); Like 'Nabal' (5); West-Indian } \\
\text { type (6) }\end{array}$ \\
\hline Ease of peeling & Excellent (1); Good (2); Medium (3) Difficult (4): Impossible (5) \\
\hline \multicolumn{2}{|r|}{ 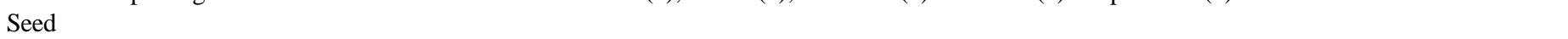 } \\
\hline Separation of seed from flesh & Easily (1): With some difficulty (2); Impossible (3) \\
\hline Weight (\% of fruit weight) & $<6 \%(1) ; 6 \%-10 \%(2) ; 11 \%-15 \%(3) ; 16 \%-20 \%(4): 21 \%-25 \%(5) ; 26 \%-30 \%(6) ;>30 \%(7)$ \\
\hline Surface & Smooth ( I); Pebbled (2); Ridged (3) \\
\hline \multicolumn{2}{|r|}{ (2) } \\
\hline Fibers & $\begin{array}{l}\text { None (1); A few (colorless) (2): A few (colored) (3); Apparent (colorless) (4): Apparent (colored) } \\
\text { (5); Numerous (6); Woody fibers (7) }\end{array}$ \\
\hline Bitterness & None (1); Slight (2); Medium (3); Strong (4) \\
\hline Sweetness & Strong (1); Medium (2): Slight (3): None (4) \\
\hline Aroma (nut-like flavor) & Strong (1); Medium (2); Weak (3): None (4) \\
\hline Taste evaluation & Excellent (1); Very good (2); Good (3); Poor (4); Bad (5) \\
\hline Darkening of cut surface ( $6 \mathrm{~h}$ after cutting) & None (1); Slight (2); Severe (3) \\
\hline \multicolumn{2}{|l|}{ Storage } \\
\hline Harvest to softening time (room temperature) & $\begin{array}{l}<6 \text { days (1): } 6-10 \text { days (2): } 11-15 \text { days (3); 16-20 days (4); } 21-25 \text { days (5); 26-30 days (6); >30 } \\
\text { days ( } 7 \text { ) }\end{array}$ \\
\hline Shelf life & In days \\
\hline
\end{tabular}

$\overline{\text { 'Degrees of evaluation not included in analysis, }}$ 
Table 2. Mango traits analysed in comparison of seedlings and grafted plants.

\begin{tabular}{ll}
\hline \hline Trait & \multicolumn{1}{c}{ Degree of evaluation } \\
Flowering intensity & Profuse (1); High (2); Medium (3); Light (4) Very light (5); None (6) \\
Tree habit & Weeping (1); Domed (2); Upright (3) \\
Mature leaf color & Light-green (1); Green (2); Dark-green (3) \\
Harvest to softening interval & In days \\
Fruit weight & In grams \\
Fruit color & Green and/or yellow (1); Pink-red matte cheek (2); Red-pink cheek (3); Fully red (4); Shining red (5) \\
Shin blemishes & Many (1); Medium (2): None (3) \\
Flesh color & Yellow (1); Light-orange (2); Dark-orange (3) \\
Fibers & Many (1); Few (2); None (3) \\
Internal defects & Many (1); Moderate damage (2); None (3)
\end{tabular}

grafted on young rootstock in the nursery and also topworked grafts (one to three trees each). The other 159 seedlings were grafted in only one of the two methods. Evaluation of productivity (in five grades) was averaged for all the grafted trees of the same seedling. The same trait in the 70 original seedlings and their grafted duplicates was evaluated in 4 degrees of evaluation only (see fruit density on the tree in Table 1).

Comparison between mango seedlings and their grafted trees was conducted at the Bsor Experiment Station in the southwest of Israel (Lavi et al., 1989). Seedlings were planted in a breeding plot at distances of $4 \times 2 \mathrm{~m}$. Seven interesting seedlings were selected and each was grafted on seven ' $13 / 1$ ' polyembryonic seedling rootstocks (Gazit and Kadman, 1980). A comparison ofthe performance of the original seedling with its grafted duplicates for 10 traits was carried out 4 years after grafting.

Seedlings and grafted trees of avocado and mango were located in the same orchard, under similar soil and climatic conditions. Similar agrotechniques were performed for the seedlings and for their grafted duplicates. However, the grafted duplicates were usually prepared only after seedlings were selected, at the age of 6 to 10 years. Thus, as a rule, evaluation of the original seedlings and their grafted duplicates was performed in different years. Only once did we have the opportunity to compare the performance of seedlings and their grafted duplicates at the same period of time. In that case, graftwood was taken from 12 seedlings in the nursery and seedlings and their grafted duplicates were planted, side by side, at the selection plot.

Evaluation of avocado and mango seedlings and grafted duplicates was based either on measurements or on visual scoring (Tables 1 and 2). Two-way analysis of variance was carried out for each trait between seedlings and their grafts by Program GLM of SAS (SAS Institute, 1989).

Table 3. Avocado fruits in which significant main effect difference between performance of seedlings and their grafted duplicates were detected,

\begin{tabular}{lcccc}
\hline & $\begin{array}{c}\text { Seedling } \\
\text { average }\end{array}$ & $\begin{array}{c}\text { Graft } \\
\text { average }\end{array}$ & $\begin{array}{c}\text { F } \\
\text { value }\end{array}$ & $P$ \\
Trait & 1.61 & 1.92 & 11.25 & 0.0012 \\
Tree habit & 3.53 & 3.03 & 14.70 & 0.0003 \\
Flowering intensity & 2.93 & 2.65 & 4.28 & 0.0417 \\
Fruit density & 279 & 296 & 5.50 & 0.0217 \\
Fruit weight (g) & 1.71 & 1.93 & 4.19 & 0.0435 \\
Length of peciuncle & 2.35 & 2.14 & 11.78 & 0.0010 \\
Skin thickness & 3.22 & 3.55 & 20.00 & 0.0001 \\
Aroma & 3.26 & 3.42 & 6.15 & 0.0156 \\
Taste evaltation & & &
\end{tabular}

\section{Results}

Avocado. Thirty-five traits having gradual trends in evaluation were compared. For 17 traits no significant differences were found between the performance of the original seedlings and their grafted duplicates. These traits were tree size; foliage density; leaf anise odor; flowering time; length of pedicel; fruit stalk thickness; damage by snap picking; fruit skin gloss, surface, and ease of peeling; seed weight; flesh fibers, bitterness, sweetness, and darkening; time from harvest to softening and shelf life. For eight traits, significant main effect differences were detected between the performance of the seedlings and those of their grafts (Table 3). For the remaining ten traits a significant interaction was detected between the performance of the original seedlings and that of their grafted trees (Table 4). However, in all these cases the difference was relatively small in relation to the 2 to 7 degrees of evacuation (Table 1).

The comparison carried out concurrently on the second population of seedlings and their grafted trees grown side by side confirmed these findings. Also in this case, no significant differences between seedlings and their grafted plants were found in any trait but one. A significant difference $(P<0.22 ; \mathrm{F}=0.55)$ was found in flowering intensity; the grafted trees flowered more intensively than the seedlings (4.18 grades vs. 5.5, respectively). Contradictory results between the data of this plot and the previous analysis were found only in leaf size. The productivity distribution of the grafted trees is presented in Fig. 1 and the correlation $(R=$

Table 4. Avocado and mango traits in which significant seedling $\mathrm{x}$ graft interactions were detected.

\begin{tabular}{lcccc}
\hline Trait & $\begin{array}{c}\text { Seedling } \\
\text { average }\end{array}$ & $\begin{array}{c}\text { Graft } \\
\text { average }\end{array}$ & $\begin{array}{c}\text { F } \\
\text { value }\end{array}$ & $P$ \\
\hline & $\begin{array}{c}\text { Avocado } \\
\text { Mature leaf color }\end{array}$ & & & \\
Leaf size & 2.44 & 2.29 & 2.13 & 0.0007 \\
Flush color & 2.87 & 3.12 & 1.94 & 0.0026 \\
Lenticels on young shoots & 3.01 & 2.69 & 1.98 & 0.0021 \\
Leaf margin & 1.39 & 1.63 & 1.66 & 0.0163 \\
Fruit size uniformity & 1.39 & 1.21 & 1.72 & 0.0141 \\
Fruit shape uniformity & 1.40 & 1.14 & 2.01 & 0.0024 \\
Fruit stalk attachment & 1.68 & 1.51 & 1.69 & 0.0173 \\
Separation of seed from flesh & 1.10 & 1.04 & 5.49 & 0.0001 \\
Seed surface & 1.57 & 2.43 & 3.13 & 0.0021 \\
& Mango & & & \\
Flowering intensity & 2.00 & 1.48 & 2.55 & 0.0397 \\
Mature leaf color & 2.00 & 2.09 & 2.96 & 0.0212
\end{tabular}


$0.55^{* * *}$ ) between the productivity of the seedlings and that of their grafted duplicates in Fig. 2. It seems that the productivity variation of the grafted trees is less extreme than that of the seedlings. Highyielding selections yielded less as grafted trees while low-yielding selections produced more fruit after being grafted. A change of one grade in the seedling productivity was paralleled by an average change of 0.5 grade in that of its grafted duplicate.

Mango. Out of the ten traits evaluated, eight traits showed no significant differences between the performance of the original seedlings and that of their grafted duplicates. These were tree habit; harvest to softening interval; fruit weight; fruit color; skin blemishes; and flesh color, fibers, and internal defects. For only two traits, flower intensity and mature leaf color, a significant seedling $\times$ graft interaction was detected (Table 3 ).

\section{Discussion}

Avocado and mango breeding projects are based on selection of ungrafted seedlings, which are later grafted for the final assessment. Therefore, it is very important to study the possible effects of rootstock on the performance of seedling scions. We are not aware of any other comparison carried out between fruit-tree seedlings and their own grafted trees. Our findings and analyses for avocado and mango (Tables 3 and 4) indicate that there was no difference of practical importance between the original seedlings and their grafted duplicates, even though some minor differences were found.

Some of the traits significant] y affected by grafting in avocado may be interrelated. Reduced flowering intensity found in grafted avocado trees may have resulted in lower production (expressed as fruit density) and therefore resulted in larger fruit as compared with the seedlings. Similarly, less aroma (nut-like flavor) resulted in lower general taste evaluation in the grafted avocados as compared with the seedlings. Reduced vegetative growth by grafting probably resulted in smaller trees and leaf sizes as compared with the ungafted seedlings.

It is interesting to note that grafting had the same effect on flowering intensity in both avocado and mango. In both species, seedlings flowered less heavily than their grafted duplicates. This might indicate some residual juvenility of the seedlings.

Mature leaf color was affected by grafting in avocado and mango. Leaves were darker in grafted mangos but lighter in grafted avocados as compared with their ungrafted seedlings. We have no explanation for this phenomenon.

The narrower range of production of grafted trees as compared with their parallel seedlings (Fig. 2) may result from the fact that only one original seedling was compared in each case with several grafted trees. Thus, each seedling had its own unique environmental conditions, whereas the conditions for grafted trees were avenged for several individuals. However, the very high and significant relationship between the yields of the seedlings and their grafted duplicates indicates that both are similar regarding the breeding objectives and hence may be used for avocado seedling selection. This conclusion is emphasized by the fact that similar results were obtained in the comparison of the group of seedlings which were assessed in the same plot and the same year with their grafted duplicates.

A fixed-effects statistical model was used in this study and therefore the conclusions are restricted to the seedling populations analysed. Although we found some statistically significant interactions or main effects, they are of no practical importance, since the differences were relatively small in relation to the two to seven grades of evaluation and were, therefore, of minor importance for

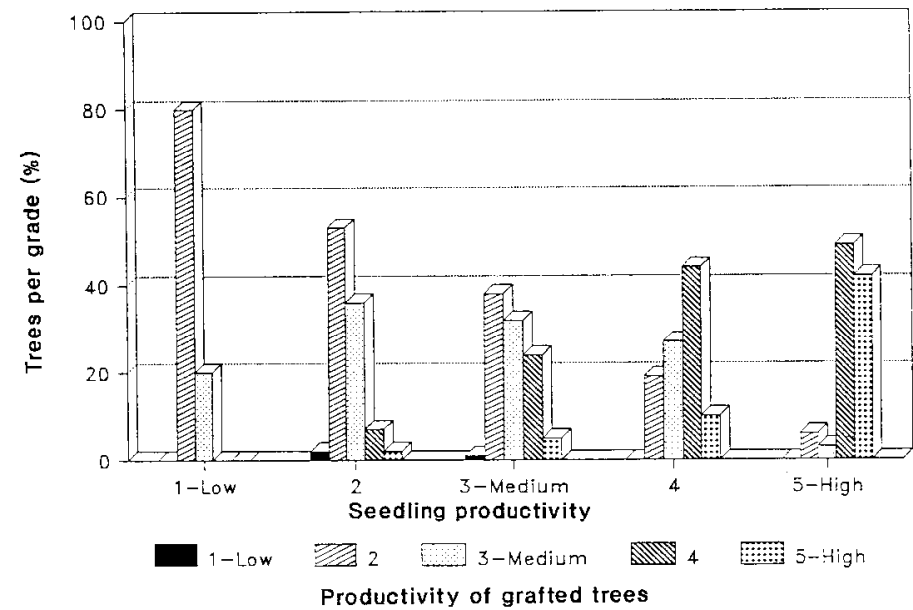

Fig. 1. Productivity distribution of grafted avocado trees relative to their original seedlings

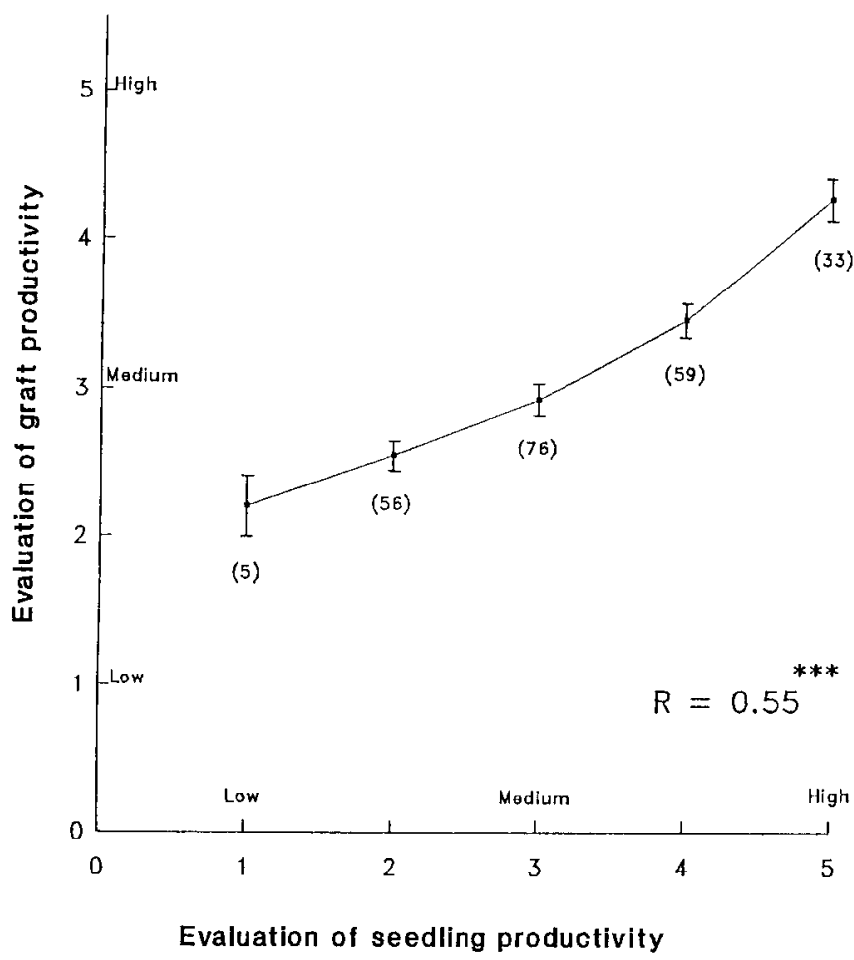

Fig. 2. Avocado seedling productivity $( \pm \mathrm{SE})$ as related to their grafted duplicates. Number in parentheses are numbers of selections per grade.

the breeder. A significant interaction suggests that the difference in performance between the original seedling and its grafted duplicates is not a general effect of the rootstock but is rather limited to some seedlings and their grafts. We had expected environmental effects to cause some differences between the performances of seedlings and that of their grafts in traits having low heritability (Lavi et al., 1993) and also to find differences due to assessment errors by the experimenters, but such differences were not detected. Rootstock might have affected scion performance positively or negatively, especially in regard to productivity (Ben-Ya'acov, 1987). In this study no significant rootstock effect 
on productivity was found. This discrepancy may be the result of the fact that wc used only recommended rootstock.

The conclusion for avocado and mango breeders is that breeding programs for the above mentioned traits could be carried out on ungrafted seedlings. No significant practical differences are to be expected between the performances of the seedlings and that of their grafted duplicates.

\section{Literature Cited}

Ben-Ya'acov, A. 1972. Avocado rootstock-scion relationships: A longterm large-scale field research project. California Avocado Soc. Yrbk. 55:158-161.

Ben-Ya'acov A. 1987. Avocado rootstock scion relationships. South African Avocado Growers' Assn. Yrbk. 10:30-32.

Ben-Ya'acov. A., E. Michelson, and I. Sela. 1979. Field trial to check rootstock and scion resources in commercial avocado plantations: Summary of 10 years research 1968-1978. Israel Agr. Res. Org., The Volcani Center, Internal Publ.

Bergh, B.O. and P.H. Whitsell. 1962. A possible dwarfing rootstock for avocados. California Avocado Sot. Yrbk. 44:55-62.

Coffey, M.D. 1987. Phytophthora root rot of avocado. Plant Dis. 71: 10461052.

Gazit S. and A. Kadman. 1980. 13-1 mango rootstock selection. HortScience 15:669.

Giri, A. and M. Yacub. 1965. A comparative study of seed germinating and seedling vigor of grafted and seedling mangoes. Pakistan J. Agr. Res. 3:138-144.

Janhati, O.S. 1972. Rootstock studies in Mangifera indica L. Acta Hort. 24:107-109.
Kadman, A. and A. Ben-Ya'acov. 1976. Selection of avocado rootstock for saline conditions, Acta Hort, 57: 189-1 97.

Lahav, E., D. Zamet, S. Gazit, and U. Lavi. 1986, Girdling as a means of shortening the juvenile period of avocado seedlings, HortScience 21:1038-1039.

Lavi, U., E. Lahav, C. Degani, S. Gazit, and J. Hillel. 1993. Genetic variance components and heritabilities of several avocado traits. J. Amer. Soc. Hort. Sci. 118:400-404.

Lavi, U., E. Lahav, A. Genizi, C. Degani, S. Gazit, and J. Hillel. 1990. Quantitative genetic analysis of avocado traits and cultivars. Plant Breeding 106: 149-160.

Lavi, U., E. Tomer, and S. Gazit. 1989. Inheritance of agriculturally important traits in mango. Euphytica 4:5-10.

Oppenheimer, C. 1958. A stock-scion trial with the mango in Israel. Hort. Adv. 2:27-36.

Oppenheimer, C. 1960. A stink-scion trial with avocado. Ktavim 10(1):21-27. Oppenheimer, C. 1968. A second stock-scion trial with mango in Israel. Expt. Agr. 4:209-218.

Popenoe, W. 1939. Manual of tropical and subtropical fruits. Macmillan, New York.

Rem, R.C. and R.F. Carlson, (eds.). 1987. Rootstock for fruit crops. Wiley, New York.

SAS Institute. 1989. SAS user's guide: Statistics, SAS Inst., Cary N.C. Sen, P.K. 1939. Annual Report Fruit Research Station, Sabour. Patna, Bihar, India, Supt. Govt. Printing.

Swamy, G.S., B.V. Rama Rao, and Raju D. Subramanyam. 1972, Poly embryonic rootstock for mango. Acts Hort. 2:110-113.

Tomer, E. and R. Rotem. 1989. Average yield of different avocado cultivars in the Negev area. Alon Hanotea 44:191-194.

Tukey, H.B. 1964. Dwarfed fruit trees. MacMillan. New York. p. 11-27, Wutscher, H.K. 1979. Citrus rootstock. Hort. Rev. 1:237-269. 